\title{
Duplicação e originalidade em uma adaptação fílmica do romance $O$ homem duplicado, de José Saramago
}

Ricardo Sobreira ${ }^{1}$

O debate quanto à dicotomia "fidelidade" versus "traição" pautou por muitos anos os estudos interdisciplinares que se propunham a analisar as interações artísticas entre a literatura e as artes performativas (MÜLlER, 2013, p. 8). Por estar muito ligado ao senso comum, o mero questionamento quanto à fidelidade ou à traição da adaptação ${ }^{2}$ relativamente ao texto adaptado tem beirado a irrelevância. Nesse sentido, Vanoye (1989, p. 17) já advertira há tempos que

Uma análise um pouco sofisticada de tais condições deveria conduzir efetivamente os leitores a renunciarem à ideia de "traição" evocada com tanta frequência quando se comparam as obras literárias à(s) sua(s) adaptação(ões) cinematográfica(s). Desde o instante em que se toma consciência das diferenças fundamentais inerentes ao próprio processo de leitura de narrativas escritas e fílmicas, a ideia de "fidelidade" [...] parece absurda. ${ }^{3}$

Para muito além das observações banais e simplificadoras que acusam determinada adaptação de ser inferior ao texto adaptado ou vice-versa, é preciso examinar com cuidado as "fricções" e "contágios" produzidos em todo o processo adaptativo. Ao fazermos isso, desmistificamos a antiga relação assimétrica entre as artes literária e cinematográfica - cristalizada no comentário próprio ao senso comum de que "o livro é sempre melhor do que o

1 Doutor em letras e professor da Universidade Federal do Vale do Jequitinhonha e Mucuri (UFVJM), Diamantina, MG, Brasil. E-mail: ricardosobreira@hotmail.com

2 Como aponta Mouren (1993), a arte cinematográfica, por ser ainda bastante jovem, não possui um vocabulário profundamente fixado. O próprio termo adaptação pode ser, por exemplo, diferenciado de processos de "contaminação", "narrativização", entre outros. Dada essa complexidade, entendemos o termo "adaptação", neste contexto, como um conjunto amplo de processos criativos inerentes ao desenvolvimento de um produto cinematográfico a partir de hipotexto(s) escrito(s). Para evitar repetições, algumas vezes nos referimos à "adaptação" por meio de termos mais ou menos sinonímicos, no âmbito do presente estudo, como transposição fílmica ou midiática, recriação fílmica, intermidial ou performativa, transposição literária ou intermidial, transposição fílmico-literária etc.

3 Salvo quando indicado na bibliografia, todas as traduções livres utilizadas no presente trabalho são de responsabilidade do autor da pesquisa. 
filme" - e adentramos uma discussão muito mais qualificada dessas relações em termos de intertextualidades (STAM, 2000, p. 209-210) e intermidialidades (RAJEWSKy, 2005; ClüVER, 2006). Nesse sentido, trabalhos acadêmicos presos exclusivamente às noções de fidelidade e de infidelidade costumam produzir conclusões valorativas simplificadoras justamente por incorporarem uma perspectiva unidirecional entre a adaptação e o texto adaptado (MüLLER, 2013, p. 8-9), e por desconsiderarem outras instâncias dessas relações significativas entre textos e meios de comunicação.

A relação binária entre texto "fonte" (ou hipotexto) e recriação fílmica (ou hipertexto) - implícita no debate sobre a fidelidade - revela-se, sobretudo a partir da virada pós-estruturalista, muito mais complexa quando se analisa a dificuldade em estabelecer um "original" (STAM, 2006, p. 21) ou um completo espelhamento entre a obra e sua(s) adaptação(ões).

Com o intuito de investigarmos mais detidamente essa problemática, analisamos duas obras recentes que possibilitam esse debate: o filme Enemy (2013), dirigido pelo realizador canadense Denis Villeneuve, que é uma adaptação do romance $O$ homem duplicado (2002), do autor português José Saramago. Tanto o filme quanto o livro narram as desventuras de um pacato professor de história ao descobrir que possui um duplo de si mesmo em atuação no cinema.

Tendo em vista essa delimitação no tocante aos objetos de investigação e às especificidades da pesquisa aqui empreendida, optamos por organizar o presente estudo em quatro seções. Na primeira delas, discutimos as problemáticas relações envolvidas na transposição fílmico-literária de O homem duplicado em termos da ideia de "originalidade" ou da remissão a um determinado "original” idealizado. Na segunda parte, apontamos possíveis afinidades e vias de diálogo entre as obras do autor português e as produções cinematográficas de Denis Villeneuve. A seção seguinte é dedicada à tentativa de estabelecer uma análise comparativa especificamente entre elementos romanescos do livro adaptado e as traduções intersemióticas operadas pelo diretor canadense na composição de sua adaptação. No referido subtópico, daremos especial enfoque à reacentuação do tema das ansiedades psicológicas masculinas e à composição das personagens principais por meio da criação de símbolos e de metáforas em linguagem audiovisual. Na seção final, apontamos algumas considerações finais com base na argumentação empreendida ao 
longo do estudo, com vistas à reavaliação do processo adaptativo e das noções tradicionais de originalidade e de fidelidade.

\section{O curioso caso do "espectador-expectador"}

Alguns críticos e parte do público receberam o filme de Villeneuve com relativa hostilidade (EHRLICH, 2013) devido ao fato de o diretor canadense ter enfrentado "problemas" para adaptar o livro (Mourinha, 2014) e ter supostamente "traído" o "original", ao "alterar" elementos da trama romanesca e ao introduzir personagens e situações não ideadas "originalmente" por Saramago. Algumas das reações do público podem ser visualizadas até hoje em redes sociais massivas como o Twitter, por meio de hashtags criadas durante o lançamento do longa-metragem, por exemplo: \#OhomemDuplicado e \#Enemy, entre outras. Ainda que amostras colhidas nessas redes sociais sejam muito diversificadas e de difícil sistematização científica, podemos observar que parte dos usuários, de diferentes idades e nacionalidades, relatam uma certa frustração atinente ao final do filme e à sua suposta "traição" à obra literária. Embora a tabulação e a validação dessas impressões populares fujam ao escopo deste trabalho, não podemos deixar de notar que tais comentários informais revelam um sentimento de insatisfação quanto ao tratamento dado ao livro, gerado em certa medida por um entendimento muito simplificador e dicotômico da adaptação.

Vonoye (1989, p. 22) explica que "certas decepções são com frequência provenientes do confronto entre as imagens de outrem (o arranjo de imagens feito pelo outro) e as imagens [previamente] geradas de uma personagem ou do conjunto de determinada narrativa”. Por mais que o espectador tenha consciência de que a chamada "fidelidade absoluta" (Mitterand, 2014, p. 16) seja impossível, ainda assim, se ele já teve contato com a obra adaptada, não deixará de criar determinadas expectativas e de sentir-se decepcionado caso estas não sejam de alguma maneira atendidas. Nesse sentido, o espectador converte-se em um expectador, pois espera ver recriado, transposto ou incorporado na tela, como diria Vanoye (1989), um conjunto de situações e imagens já projetado pelo texto adaptado. Hutcheon (2006, p. 8) conclui que "experienciamos adaptações [...] como palimpsestos por meio da nossa memória que estabelece enlaces [verbo-visuais] a partir de repetições com variações". Ou seja, uma "memória", um efeito "palimpsesto" (GenetTe, 1982), do texto 
adaptado permanece na mente do "espectador-expectador" quando este assiste a determinada história ser repetida (mas nunca replicada) em um novo suporte.

Entretanto, muitos teóricos chamam a atenção para a necessidade de repensarmos justamente essas expectativas em relação ao "original", no sentido de que não podemos encarar a transposição fílmica de um romance em termos de perdas (STAM, 2006, p. 20). Em trabalhos recentes, críticos como Jameson chegam até mesmo a defender que o texto adaptado e sua respetiva adaptação deveriam ser totalmente diferentes:

Eis aqui minha conclusão no tocante à adaptação cinematográfica: ela funciona somente se os dois artefatos forem radicalmente distintos não apenas na intenção mas também na verdade que expressam; se cada um fala por si e se, de fato, um não for mais uma réplica do outro, de modo que, em certo sentido, o próprio significado do termo 'adaptação' é completamente minado (JAMESON, 2015, p. 207).

O texto de Saramago, como sabemos, não é o ponto inicial do tema do duplo. Esse leitmotiv, na verdade, é um dos mais antigos e recorrentes da literatura ocidental, cuja retomada se dá de tempos em tempos por um processo contínuo de intertextualidades temáticas (Koch; Bentes; CAVAlcante, 2007, p. 18-19). O próprio Saramago confessou ter-se inspirado na peça clássica Anfitrião (séc. III-II a.C.) do comediógrafo romano Plauto (IbÁÑEZ; JuRAdo, 2004) para compor O homem duplicado. Mas esse tema tem uma longa trajetória, que passa inclusive por A comédia dos erros (1594), de Shakespeare; "William Wilson" (1839), de Poe; O duplo (1846), de Dostoiévski; "A sombra" (1847), de Andersen; O médico e o monstro (1886), de Stevenson; O retrato de Dorian Gray (189o), de Wilde; “As Sabines" (1943), de Aymé; "O outro" (1975), de Borges; etc. Por essa razão, torna-se uma tarefa árdua diferenciar rigorosamente, nas sociedades cada vez mais semiotizadas em que vivemos, entre original e cópia. O próprio filme Enemy, de Villeneuve, além de adaptado do romance de Saramago, é também inspirado no cinema enigmático de Stanley Kubrick (BELANGER, 2014). Do mesmo modo, nota-se um diálogo com diversos outros filmes sobre doppelgängers, a exemplo de Dead Ringers (1988), com roteiro e direção do colega canadense de Villeneuve, David Cronenberg (LANe, 2014, p. 78; RAmond, 2014, p. 53). Embora não tenha sido explicitado pelo realizador nem pelo roteirista (Javier Gullón), podem-se também reconhecer nas situações insólitas do enredo alguns traços kafkianos, como a sugestão de atmosferas de pesadelo, ansiedade e estranhamento. 
Stam (2006, p. 24; 2008, p. 19-22) observa que, no momento histórico em que vivemos, marcadamente mundializado e repleto de imagens e de simulações, a adaptação se torna apenas um outro texto, parte de um amplo contínuo discursivo. Por essa razão, devemos entender as transposições fílmicas de textos literários como um intricado processo adaptativo envolvendo a intersemiose, isto é, como um conjunto de relações entre diferentes tipos de linguagens, pertencentes a códigos semióticos de natureza diversa (JAKOBSON, 1991, p. 65,72; VIEIRA, 2005, p. 119; SobreIRA, 2015). Além disso, adaptações cinematográficas de obras literárias conjugam intermidialidades (RAJEWSKY, 2005) ao promover transposições midiáticas do substrato de um meio de comunicação para outro diferente e/ou ao possibilitar uma combinação midiática em que diferentes meios (no caso, o livro e o cinema) se integram com vistas à constituição e à significação de um produto intermidiático resultante.

Dado o caráter intersemiótico das adaptações cinematográficas em geral, e de Enemy em específico, buscamos, no que segue, estabelecer vias de diálogo entre produções do romancista português e do diretor da recriação intermidial em análise.

\section{Considerações sobre os autores do romance e da transposição fílmica}

Respeitadas as devidas proporções, pode-se verificar que há afinidades temáticas e estilísticas entre os projetos estéticos do cineasta canadense e do escritor português.

Desde Memorial do convento (1982), José Saramago rompe com as principais vertentes neorrealistas - cujas preocupações se voltam para o estabelecimento literário de uma ilusão documental - e aproxima-se de um tipo de "realismo artístico" mais imaginativo e criativo. Essa orientação em favor do sobrenatural e do maravilhoso, mas sem perder de vista o real, faz com que o autor ganhador do prêmio Nobel seja por vezes comparado estilisticamente a escritores latino-americanos associados ao chamado realismo mágico ou fantástico (CALBUCCI, 1999, p. 20-22). Sua escrita torrencial, por vezes lúdica e coloquial, que confere um grande valor à imaginação e à fantasia e subverte as convenções tradicionais da pontuação e da formatação de diálogos (MoIsÉs, 2013, p. 526-528), busca forjar uma linguagem própria a fim de plasmar as complicadas relações do homem moderno com seu passado histórico e com sua(s) identidade(s). Seus romances experimentais ambientados na 
contemporaneidade: Ensaio sobre a cegueira (1995), A caverna (200o), As intermitências da morte (2005), etc., com frequência projetam sujeitos fragmentados em busca de sua identidade em uma grande cidade impessoal e afligida por algum acontecimento bizarro, capaz de pôr em questionamento os limites da própria realidade.

Nessa mesma linha, Denis Villeneuve é um jovem realizador quebequense que, assim como Saramago, demonstra, em sua obra, grande preocupação com a vida nas grandes metrópoles. Esse auteur pertence a uma geração de cineastas que rompem com uma visão tradicional do Canadá vinculada à natureza e faz, por meio de suas histórias, uma crítica contundente à alienação provocada pela vida urbana. Desde filmes anteriores como Un 32 août sur terre (1998) e Maelström (200o), a cidade é representada por Villeneuve em tons sombrios, como um espaço que foi "transformado pelo poder da cultura corporativa global em um local distópico e desalmado, caracterizado pelo anonimato claustrofóbico e pelo funcionalismo [arquitetônico] redundante" (MELnYK, 2014, p. 91-92). Essa mesma estética, tributária do film noir, pode ser percebida em Prisoners (2013) e em Enemy. A fotografia deste último explora, além das tonalidades sombrias, uma paleta em tons sépia - desde o amarelo até filtros esverdeados e cinza-escuro - que sugerem um ambiente doentio, claustrofóbico e ameaçador. As personagens são enquadradas em contato direto com o tecido urbano, frequentemente vivendo e trabalhando "aprisionadas" em estruturas de concreto armado, aço e vidro, cercadas por muros e paredes de cimento, ou isoladas sobre calçadas e túneis escuros, estacionamentos cinzentos e assentos públicos fixos e rígidos. Melnyk (2014, p. 97-98) observa que, no cinema de Villeneuve, "a cidade, em sua manifestação concreta, é imóvel, dura, impermeável e inflexível ao contato humano" e que, portanto, o centro urbano, com suas ocorrências estranhas, espelha o estado psicológico dessas personagens anônimas e sem autonomia.

Apesar dessas potenciais afinidades compartilhadas por obras de Saramago e de Villeneuve - a preocupação com questões sociais voltadas para o sujeito humano fragmentado, habitante de grandes centros urbanos desumanizadores, e a incorporação de elementos fantásticos em suas narrativas -, notamos algumas "fricções" e "contágios" provocados nas interações entre ambos os textos ( $O$ homem duplicado e Enemy), cujos enredos comparamos a seguir.

No romance adaptado (Saramago, 2002), Tertuliano Máximo Afonso é um professor de história em um colégio de ensino básico. Recentemente 
divorciado, o docente de 38 anos vive sozinho em um apartamento simples e dedica seu pouco tempo livre à leitura de livros sobre as antigas civilizações mesopotâmicas. Tertuliano mantém um relacionamento intermitente com uma funcionária bancária, Maria da Paz. Sua vida tediosa passa por uma grande transformação quando aluga um filme recomendado por um colega do trabalho. No filme, Tertuliano descobre um ator que é uma cópia absolutamente idêntica de si mesmo. Após uma longa e obsessiva pesquisa em fitas vHs e através de uma carta escrita à produtora dos filmes, o professor descobre que seu sósia é um ator chamado António Claro, cujo nome artístico é Daniel Santa-Clara (em uma provável alusão de Saramago à santa padroeira da televisão). Tertuliano entra em contato com António, que, inicialmente, reluta em querer conhecê-lo, mas acaba por marcar um encontro, ao qual, por precaução, comparece armado. A partir do primeiro telefonema de Tertuliano, a esposa de António, Helena, passa a se sentir ameaçada por esse outro. Os dois homens se encontram em uma vivenda no campo e, após exame de seus corpos nus, chegam à conclusão de que são realmente idênticos em tudo, inclusive na voz. Há apenas uma pequena diferença de horários de nascimentos - o que, em tese, faria de António o "original" e, de Tertuliano, a "cópia".

Certo tempo depois desse primeiro encontro, Tertuliano envia a António a barba postiça que utilizava quando saía para vigiar sua vida sem que fosse confundido com o ator. Sentindo-se ameaçado e, ao mesmo tempo, provocado, António passa a espionar a vida de Tertuliano e se interessa pela noiva de seu duplo, Maria da Paz. Ao contrário de Helena, Maria da Paz não sabe da existência de um sósia de seu namorado, ainda que desconfie muito do comportamento estranho do parceiro nos últimos meses. Motivado por seu próprio desejo de desforra e por uma curiosidade perversa, António força Tertuliano a trocar de roupas e de carro consigo e vai encontrar-se com Maria da Paz passando-se pelo professor de história. Tertuliano também decide vingar-se de António e, ao fingir ser o ator, toma posse de seus objetos pessoais e de seu automóvel, e dorme com Helena como se fosse seu esposo. Na manhã seguinte, Tertuliano descobre que António e Maria da Paz morreram em um desastre de trânsito após terem passado a noite juntos na vivenda. Maria da Paz havia descoberto pela manhã que o homem com quem dormira não era seu noivo e, durante o trajeto de volta, acabaram trocando empurrões, o que culminou no acidente. Perplexo e desorientado, Tertuliano, após conversar com 
sua mãe e depois de contar toda a verdade a Helena, resolve assumir permanentemente o lugar de António. A identidade pública do professor de história é sepultada junto com o corpo do ator. Tertuliano passa a viver a vida do outro, com o consentimento de Helena. No último capítulo, António (que, na verdade, é Tertuliano) recebe um telefonema insólito de outro homem com uma voz idêntica à sua, que declara ser seu sósia e pede um encontro. António/Tertuliano concorda em reunir-se com essa outra cópia de si, saca a pistola e sai apressado.

A narrativa de Saramago é acentuadamente visual, pois, além de fazer inúmeras alusões diegéticas ao cinema e ao vídeo, também projeta, por meio do fluxo narrativo torrencial e episódico, uma espécie de linguagem cinematográfica que parece oferecer-se à recriação em modo "mostrar" ou "performativo", como diria Hutcheon (2006, p. 22-27).

A adaptação cinematográfica do romance recebeu o título de Enemy, mas em vários países foi lançado com o mesmo título do livro. Trata-se de um thriller psicológico falado inteiramente em inglês. O roteiro do filme, uma coprodução canadense e espanhola, é uma transposição relativamente livre do texto de Saramago. Ao contrário do romance do autor português - no qual não se especifica onde se passa a história -, na adaptação fílmica toda a ação é ambientada em Toronto. O herói, Adam Bell, é um professor universitário depressivo, que divide seu tempo entre suas aulas de história e uma relação apática com sua namorada, Mary. Essa situação de apatia é quebrada quando o professor assiste a um filme e descobre que um dos figurantes é fisicamente idêntico a si. A partir daí, Adam inicia uma busca obsessiva por esse duplo, que se revela ser o ator Daniel St. Claire, nome artístico de Anthony Claire. Anthony é casado com Helen, que está grávida. Após algumas tentativas de estabelecer contato, Adam consegue se encontrar com Anthony em um hotel. Apesar de serem idênticos fisicamente, ambos têm temperamentos distintos: Adam é introvertido, e Anthony possui um perfil mais violento e erotizado. O professor Adam percebe que essa reunião entre homens duplicados não foi uma boa ideia e vai visitar sua mãe para lhe perguntar se ele não teria um irmão gêmeo. A mãe reage negativamente a essa pergunta.

A partir desse instante, surge no horizonte da metrópole canadense uma aranha de tamanho descomunal a mover-se sobre os edifícios - uma presença quase tão ameaçadora quanto as espaçonaves alienígenas do mais recente filme de Villeneuve, Arrival (2016). Essa cena incomum incluída em Enemy, 
no entanto, não parece provocar qualquer reação de pânico nos habitantes da cidade, que seguem uma rotina normal de qualquer grande espaço urbano. $\mathrm{O}$ ator e sua esposa também passam a desenvolver interesse pelas vidas de Adam e de sua namorada. Dessa forma, as vidas do professor de história e do ator colidem e começam a se confundir. Após espionar Mary em seu trabalho, Anthony acusa Adam de ter dormido com sua esposa e, ao se apossar de seus pertences, passa-se pelo professor e faz sexo com Mary. De forma análoga, Adam infiltra-se no apartamento de Anthony e vai para a cama com Helen, que percebe a diferença entre ambos os homens, mas pede ao sósia de seu marido que não a deixe. Enquanto isso, Mary entra em pânico ao descobrir que o homem com quem se encontrou não é seu namorado. Enquanto Anthony leva-a para casa, os dois discutem e entram em um confronto físico, que acaba num terrível acidente automobilístico, provavelmente causando a morte de ambos. Adam se convence de que deve seguir sua vida com a identidade de Anthony. Helen, na manhã seguinte, age como se nada tivesse acontecido e, ao sair do banho, entra no dormitório. Adam pergunta se ela tem planos para mais tarde. Helen não responde. Ele então a informa (embora ela já esteja fora de campo na tela) de que estará ocupado logo mais à noite. Ao se virar, Adam vê, em lugar de Helen, uma aranha gigante a tomar conta do dormitório do casal. O professor de história não esboça nenhuma surpresa ou medo em relação a essa ocorrência bizarra, apenas um leve suspiro de resignação.

\section{Construção audiovisual de símbolos sugestivos do psiquismo do herói}

Como se pode constatar pelo exposto acima, o filme Enemy reinscreve o tema do professor de história que descobre seu duplo, bem como seus desdobramentos narrativos, presentes no romance. Ao incorporar intertextualmente essa temática (KocH; Bentes; CAVAlCANTE, 2007, p. 18-19), Villeneuve cria sua própria (re)interpretação do tema, operando permutas e modificações no material a fim de recriá-lo conforme sua visão cinematográfica. Em termos de "contágios" criativos, Villeneuve incorpora ao filme parte substancial do esquema narrativo da trama romanesca, o que acrescenta ao hipotexto escrito ainda mais dinamismo. $\mathrm{Na}$ transposição fílmico-literária, a adaptação contribui para dotar a história de mais vivacidade por meio de recursos audiovisuais como a fotografia, a edição de som, 
a montagem, a sucessão de planos etc. E embora seja relativamente difícil encontrar denominadores comuns entre literatura e cinema no tocante à representação cinematográfica de estados psicológicos íntimos das personagens tal qual se articulam na linguagem escrita (Hutcheon, 2006, p. 68-71), o diretor canadense, sempre em colaboração com o roteirista e com outros membros da equipe envolvida, encontra formas performativas de tornar audível e visível a complexa psicologia das personagens de maneira comparável à presente no texto adaptado. Além desses aspectos diegéticos e psicológicos presentes no romance, as questões filosóficas suscitadas por Tertuliano/António, no romance de Saramago, também contagiam a produção de Villeneuve no sentido de que o filme reacentua - por sua vez, através do dilema de Adam/Anthony a discussão ontológica relativa à identidade humana (RAMOND, 2014, p. 53).

Quando confrontamos o romance e o longa-metragem, percebemos também determinadas "fricções" criativas relacionadas, em grande medida, ao fato de Villeneuve ter realizado uma adaptação "transnacional” (STAM, 2006, p. 47). Apesar de o romance ser português e ambientado em uma metrópole análoga a algumas capitais europeias, o filme é falado em língua inglesa, ambientado em Toronto, com atores americanos, franceses, canadenses, italianos, jamaicanos etc. Essa mudança de cenário também torna a produção cinematográfica mais ágil que o livro em termos de densidade de incidente e ritmo da ação: Toronto - ao contrário da cidade imaginada por Saramago - é retratada de modo mais dinâmico e caótico, repleta de veículos que entrecortam a malha urbana "tecida" por uma gigantesca tarântula visível no horizonte. Além disso, a adaptação torna a trama mais atual, ancorada numa era digital dominada pela internet, em que o acesso à informação torna-se muito mais dinâmico. O romance de Saramago, apesar de ter sido publicado em 2002, parece se passar nos anos 1980, com seus telefones de disco, seus televisores analógicos e suas locadoras de fitas cassetes em vHs. O filme de Villeneuve insere a personagem do professor de história na sociedade de vigilância, em que a tecnologia digital permite invadir a privacidade de seu "outro" com muito mais eficiência e rapidez.

O romance de Saramago possui um caráter de história de detetive dada a dificuldade experimentada por Tertuliano para investigar e reunir informações a respeito de seu doppelgänger. Se na narrativa do autor português "o caos é uma ordem por decifrar" (SARAMAGO, 2002, p. 105), o herói precisa então gastar vários dias numa tentativa de decifração da situação caótica em que se vê 
envolvido. Ao longo de cinco longos capítulos, o professor é forçado a assistir a um número imenso de horas de filmagens, a manter um extenso arcabouço de anotações, a escrever uma carta para a produtora de cinema e a aguardar durante semanas pela resposta para enfim descobrir o nome de António. A adaptação de Villeneuve não expande a metragem fílmica com essa busca e, portanto, recusa-se a prolongar a porção detetivesca da narrativa, pois as mesmas informações sobre o ator são descobertas pelo professor em poucos minutos, por meio da utilização de ferramentas digitais de busca na internet em páginas virtuais que expõem a intimidade das celebridades. Os procedimentos analógicos, anacrônicos e vagarosos adotados por Tertuliano no romance não fazem mais sentido nessa metrópole global de Villeneuve, em que todos podem ser visualizados, arquivados, seguidos e compartilhados em uma fração de segundo. Por essa razão, o filme não deixa de ser um comentário alarmante sobre o fenômeno do chamado cyberstalking, isto é, sobre a facilidade com que nossas vidas, no contexto tecnológico atual, podem ser vigiadas e invadidas pelo olhar mal-intencionado de qualquer alteridade ameaçadora (Scotт 2014).

Devido ao fato de a adaptação ser transnacional, alguns nomes próprios foram alterados: em vez de António, Maria da Paz e Helena, temos, respectivamente, na adaptação de Villeneuve, as personagens Anthony, Mary e Helen. Como o nome Tertuliano Máximo Afonso soa estranho para a plateia internacional, o roteirista Javier Gullón, sob a tutela de Villeneuve, optou por chamá-lo de Adam. Mas não apenas por essa razão: ao longo de todo o romance, o narrador sempre se refere ao herói por seu nome completo, sem nunca o chamar pelo primeiro nome ou abreviar um de seus sobrenomes. Tertuliano Máximo Afonso possui "no seu bilhete de identidade um nome nada comum, de um sabor clássico que o tempo veio a tornar rançoso" (SARAMAGo, 2002, p. 11), isto é, um nome que acaba por distingui-lo (SARAmAGO, 2002, p. 54) e como tal, o herói romanesco acredita-se único no mundo. Ao tomar conhecimento de sua duplicação e, possivelmente, até de sua triplicação, Tertuliano relutantemente deixa de sentir-se indivisível para perceber-se muitos, para converter-se em uma tertúlia, em um agrupamento de indivíduos, como seu próprio nome sugere. A escolha do nome Adam na transposição midiática deve-se ao fato de este ser um nome bíblico evocativo ironicamente do homem primordial, da criatura única que foi feita de modo singular para 
habitar o planeta. O Adam de Villeneuve também vive com essa ilusão de originalidade até se descobrir, assim como Tertuliano, cópia idêntica de um outro homem. Além do nome do herói, os roteiristas também optaram por dar à adaptação um título diferente do texto adaptado. O título do filme, Enemy, faz referência à palavra "inimigo" e seus derivados, que são termos recorrentes no romance (SARAMAGO, 2002, p. 88, 216, 228, 230, 233, 260, 283, 287, 292). Entre essas várias passagens, destacamos, abaixo, a que mais denota o acirramento do antagonismo entre os duplos:

E a mulher [Helena] perguntará, Mas como pode isso ser, se tu não tens inimigos. António Claro não perderá tempo a responder-lhe que é impossível não ter inimigos, que os inimigos não nascem da nossa vontade de os ter, mas do irresistível desejo que têm eles de nos terem a nós (SARAmaGo, 2002, p. 228, grifo nosso).

Esse clima beligerante, que já estava fortemente presente no romance, adquire relevância central na transposição fílmica. Não apenas o tema da inimizade é reacentuado no próprio título da adaptação, como também ganha contornos ainda mais dramáticos ao ser encenado em linguagem audiovisual. Aquilo que no livro é sugerido paulatinamente, torna-se premente no longametragem: Adam e Anthony não podem coexistir. Como ocorre na longa tradição de narrativas sobre duplos, há tensões em jogo na sociedade que impõem a "normalização" dos indivíduos tidos como "anormais". Isso tem que ver com o fato de que

uma vez que as leis da natureza insistem que algo não pode existir em dois lugares ao mesmo tempo, um homem e seu duplo não podem continuar a coexistir: um dos dois deve ser extinto para que a ordem do universo seja preservada (MANGUEL, 2004).

Além disso, tanto o texto adaptado quanto a adaptação reinserem o trágico na tessitura narrativa e, portanto, uma espécie de harmonia e de ordem "naturais" devem ser reestabelecidas ao caos "antinatural" introduzido pela duplicação humana. Vale destacar que o final do livro evoca a linguagem dos jogos eletrônicos, nos quais padrões se repetem, batalhas não se encerram, e o herói passa à próxima fase munido de armas para combates ainda mais intensos. Em vez de deter o processo de replicação com a morte do duplo, a narrativa se aproxima das Sabines, de Aymé (2012), cujas multiplicações de sósias fogem ao controle a ponto de a personagem tornar-se onipresente. 
No entanto, certamente a diferença mais notável entre o texto adaptado e a adaptação intimista de Villeneuve é a presença, tanto no filme em si quanto em grande parte dos materiais paratextuais de divulgação do longa-metragem, das enormes aranhas. Ainda que o texto literário não aluda explicitamente a elas, ${ }^{4}$ pode-se perceber que o livro faz uma sugestiva comparação entre a barba postiça enviada pelo correio a António e um animal peçonhento. Embora este não seja especificamente associado pelo narrador a alguma espécie de aranha, é possível inferir que a criatura seja da mesma ordem desses seres capazes de inocular veneno. A esposa de António, Helena, demonstra grande preocupação com o "veneno" potencialmente contido na barba mandada por Tertuliano. Há uma provocação presente nesse objeto - que é peludo como uma tarântula, como um bicho cheio de peçonha - e por essa razão Helena aconselha o marido a destruí-lo: "Se eu me visse na tua situação, rasgava-a [a barba postiça], atirava-a fora, ou queimava-a, morrendo o bicho, acabava-se a peçonha" (SARAMAGO, 2002, p. 229, grifo nosso). A adaptação, entretanto, dá corpo a essa peçonha sob a forma de enormes tarântulas inseridas por meio de efeitos especiais em CGI (computergenerated imagery) sobre tomadas em plano geral de Toronto. As aranhas digitalmente introduzidas nas cenas posteriores à visita de Adam a sua mãe são similares à conhecida escultura, construída em bronze, aço inoxidável e mármore, pela artista francesa Louise Bourgeois, intitulada Mamãe (1999), e exposta em diversas partes do mundo, inclusive na capital canadense, Otawa. Além desse artefato, a artista também esculpiu outras aranhas gigantes em bronze como, por exemplo, a obra Aranha (1996), exposta

4 É possível que a ideia para a inserção de aranhas em Enemy tenha surgido a partir de outros romances de Saramago. Em $O$ ano da morte de Ricardo Reis (1984), o escritor português alude aos aracnídeos em vinculação com polícias repressoras de regimes fascistas ditatoriais:

A polícia fica malvista, é um descrédito para a corporação, virem sete alfaiates para matar uma aranha, e afinal a aranha fugiu, a aranha, quer dizer, a mosca, a aranha somos nós, Deixe-o ir, não faltam teias no mundo, escapa-se dumas, morre-se noutras (SARAmAGo, 2000a, p. 360).

Há também uma passagem no romance O evangelho segundo Jesus Cristo (1991) em que a personagem-título pondera sobre como a culpa é um sentimento contra o qual, o ser humano, tal qual uma mosca enredada numa teia de aranha, não tem muito como lutar:

Há um momento, quase a roçar a teia, em que a mosca ainda estaria a tempo de escapar à armadilha, mas, se chegou a tocar-lhe, se o visco filou a asa doravante inútil, qualquer movimento apenas servirá para que o insecto mais se enrede e paralise, irremediavelmente condenado, mesmo que a aranha desprezasse, por insignificante, esta peça de caça” (SARAmago, 1991, p. 2015). 
no Museu de Arte Moderna de São Paulo. Bourgeois apoia-se em sua experiência pessoal e utiliza-se com frequência - em suas esculturas, gravuras e instalações - da figura frágil e ameaçadora da aranha, que, para a artista, remete à mulher e seus papéis sociais como mãe, operária e protetora. Em Mamãe, por exemplo, a maternidade é representada "por uma espécie de enorme aranha invasora" (SEgARRA, 2008, p. 103).

Dada a centralidade das aranhas no longa-metragem, que, sem dúvida, enriquecem a representação estética do drama humano proposto por Saramago, podemos interpretar o simbolismo desses animais de diversas maneiras:

A aranha aparece primeiramente como uma epifania lunar, dedicada à fiação e à tecelagem. Seu fio evoca [...] a fragilidade. [...] E esta, por sua vez, evoca a fragilidade de uma realidade de aparências ilusórias, enganadoras. A aranha é, portanto, a artesã do tecido do mundo ou do véu das ilusões [...]. Tecelã da realidade, ela é, assim, mestra do destino [...]. Revela-se aí um conteúdo latente de ordem sexual (CheVAlier; GHeERBRANT, 1982, p. 6o-61, grifos nossos).

Como vimos, a figura da aranha está associada a estados ilusórios ou enganosos do real. Em um sentido mais particular, podemos associar as aranhas a Adam, que vive em um mundo de aparências no qual acredita ser único, um ser indivisível, mas cuja experiência contribuirá para fragmentar sua ilusão de unicidade, de identidade única e unitária. Parte dessa sensação de indivisibilidade (e, como resultado, de invencibilidade) de Adam pode também ser vinculada ao mito antigo da fiandeira Aracne, cuja prepotência, como vemos no Canto vi das Metamorfoses de Ovídio (1953, p. 259-272), é punida com sua transfiguração em aranha. É possível, ainda, associar um sentido simbólico mais geral às enormes tarântulas presentes no longa-metragem, a partir de Cirlot (2006, p. 88-89, grifo nosso):

$\mathrm{Na}$ aranha coincidem três sentidos simbólicos distintos [...]. São o da capacidade criadora da aranha, ao tecer sua teia; o de sua agressividade; e o da própria teia, como rede espiral dotada de um centro. A aranha em sua teia é um símbolo do centro do mundo e, neste sentido, é considerada [...] a eterna tecelã do véu das ilusões; a destrutividade do inseto [sic] apenas ratifica esse simbolismo da ordem do fenomênico. Por essa razão, [...] as aranhas, sempre a destruir e construir, simbolizam a inversão contínua através da qual se mantém em equilíbrio a vida do cosmo.

Nessa mesma linha, Ramond (2014, p. 53) sugere que o filme de Villeneuve propõe uma espécie de "imersão emocionante nos mistérios do inconsciente". 
O próprio realizador explicou em entrevista (MORICE, 2013) que Enemy pode ser definido como "uma exploração da intimidade masculina", que mergulha profundamente no psiquismo da personagem de Jake Gyllenhaal "a tal ponto que se poderia inclusive definir o filme como um documentário sobre seu subconsciente". Como fica evidente nesta e em outras declarações de Villeneuve, tanto Adam como Anthony são representados na adaptação como sendo o mesmo ser ficcional, isto é, um único homem a sofrer possivelmente de algum tipo de desordem identitária dissociativa e a viver uma vida dupla. Feita essa observação, não se pode tomar como literal a construção audiovisual da narrativa, pois a adaptação, como é comum na filmografia de Villeneuve, subverte a experiência realista da personagem.

Nesse sentido, o filme pode ser interpretado como um episódio angustiante vivenciado por um homem literalmente dividido entre a responsabilidade de um relacionamento estável com sua esposa grávida (Helen) e o comportamento narcisista, machista e infiel ao lado da amante (Mary). Além de estar dilacerado quanto a esses sentimentos, Adam/Anthony também se sente dividido entre a sua nova carreira "respeitável" de professor de história e a profissão glamorosa, porém instável e fracassada, de ator de segunda ordem. Todas essas complexas crises identitárias colaboram para o sentimento de ansiedade de Adam, que tenta reprimir as porções socialmente negativas de sua personalidade, isto é, encerrar o caso extraconjugal com Mary, deixar de frequentar clubes secretos de voyeurismo, ${ }^{5}$ aceitar o fim de sua carreira na indústria cinematográfica e, sobretudo, lutar contra seu maior inimigo: ele mesmo (personificado pela figura de seu alter ego, Anthony).

Essa representação psicológica do drama vivenciado por Adam/Anthony traduz-se cinematograficamente na cena em que os homens duplicados "compartilham" um pesadelo no qual veem uma criatura híbrida, com corpo de mulher nua e com cabeça de aranha, a caminhar no teto. Essa aparição insólita constitui uma metáfora visual (CARROLL, 2001, p. 347-368) que torna o

5 No início do filme, como já mencionamos, Adam/Anthony assiste, em companhia de outros homens, a uma exibição de mulheres nuas, que se masturbam atrás de uma parede de vidro. Trata-se aparentemente de um clube sigiloso para voyeurs, ao qual os participantes têm acesso por meio de uma chave secreta. Nesta mesma sequência, uma dessas strippers pisa com sapato de salto alto sobre uma tarântula em tamanho normal. Essa cena sugere o conflito psicológico vivenciado pelo herói, uma vez que este se encontra dividido entre uma vida desregrada e promíscua (simbolizada pela stripper de salto alto) e um casamento monogâmico com sua esposa gestante (simbolizada pela aranha) (ScIUs, 2014). 
feminino corporalmente indissociável do aracnídeo. A sobreposição homoespacial (CARroll, 2001, p. 354) do domínio-fonte (aranha) e do domínioalvo (mulher) produz visualmente o sentido metafórico. Tal analogia contida no pesadelo se coaduna com uma interpretação psicanalítica do aracnídeo: "uma aranha com frequência simboliza a mãe fálica e agressiva, e o medo de uma aranha representa medo do incesto e aversão aos órgãos sexuais femininos" (Wolman, 1981, p. 223). A aranha, seja por seu conteúdo sexual latente (Chevalier; Gheerbrant, 1982, p. 61), por sua capacidade criadora (Cirlot, 2006, p. 88-89) ou por sua associação à figura materna agressiva e à genitália da fêmea (Wolman, 1981, p. 223), simboliza para Adam, em um nível inconsciente, a figura ameaçadora da mulher gestante. A aranha, em algumas culturas e religiões primitivas, está relacionada à gestação do próprio mundo. Ela é responsável pela tecelagem do universo e pela criação dos seres vivos (Chevalier; Gheerbrant, 1982, p. 60-61). A gestação também está associada à produção da vida e ao engendramento do ser. Mas, como a aranha também congrega um lado destrutivo - a criação de uma teia quase invisível destinada a iludir, a aprisionar suas presas e a drenar lentamente suas vidas -, a gravidez de sua esposa é sentida pela personagem de Gyllenhaal como a destruição de sua liberdade sexual e como seu aprisionamento a uma existência de mera domesticidade.

Segundo Kimmel (2004), os códigos sociais implícitos que regulam a masculinidade dos homens heterossexuais interpretam a mulher como detentora de um lado ameaçador e potencialmente destrutivo. Em seus estudos, o pesquisador conclui que o feminino "ameaça a emasculação por representar o lar, o local de trabalho, a responsabilidade para com a família e a negação da diversão" (Kimmel, 2004, p. 191). A partir daí, podemos inferir que Adam associe todo o peso da responsabilidade familiar e da negação de qualquer divertimento masculino à figura da aranha, que, além de estar vinculada à gestação, tradicionalmente constitui um dos objetos mais comuns de fobias (Wolman, 1981, p. 223; Milosevic; McCABE, 2015, p. 34-35).

Desde as sequências iniciais do filme, as aulas do docente Adam versam sobre os mecanismos estatais de regimes ditatoriais e sobre como a história demonstra certos padrões que se repetem. Oprimido pela imposição "ditatorial" de assumir responsabilidades por sua esposa gestante (materializada através da figura recorrente da aranha), Adam tenta reprimir seu lado Anthony (playboy narcisista, irresponsável e libertino), mas acaba por falhar e repetir o mesmo 
padrão hedonista e autodestrutivo. A situação de aprisionamento no qual o herói subitamente se encontra também é sugerida em termos visuais por detalhes nas cenas como, por exemplo, o calçamento de pedras em padrão arredondado, os cabos emaranhados dos bondes que cortam a cidade e a rachadura circular no para-brisas do carro destruído de Anthony (Wickman, 2014). Todos esses detalhes visuais lembram o formato de teias de aranha, afinal, "não faltam teias no mundo, escapa-se dumas, morre-se noutras" (SARAmAgO, 200oa, p. 360). Essa interpretação pode lançar luz sobre a emblemática cena final do filme: após a morte de Anthony e de Mary, Adam acredita que conseguirá se adequar aos papéis de marido e pai de família. Porém, ao encontrar a nova chave de acesso ao clube secreto de voyeurismo, decide repetir o padrão e sair novamente em busca de prazeres licenciosos. Nesse instante, sua esposa se reconverte no símbolo de fêmea-mãe castradora, metaforizado em tarântula gigante no quarto do casal, e Adam conclui, resignado, que não há como se desvencilhar dessa vida dupla e, por conseguinte, do sentimento de culpa.

\section{Considerações finais}

Como vimos, é preciso renunciar à ideia de "traição" evocada ao compararmos a obra literária com sua(s) adaptação(ões). A relativa liberdade em relação ao romance adaptado, demonstrada por Villeneuve, está vinculada ao seu auteurisme. O realizador canadense tem construído, a partir de cada um de seus trabalhos, uma reputação de auteur (em oposição a uma postura padronizada e/ou meramente comercial) devido a seu estilo discernível em termos de mise-en-scène e de sua "assinatura" própria no tocante às técnicas cinematográficas e aos temas recorrentes. Ortiz (2014, p. 43) explica que, para um auteur conferir sua própria marca a uma obra adaptada, "é necessário tomar liberdades em relação ao original, deixá-lo de lado”.

Por essa razão, como já salientamos, a disputa entre original e cópia é tão contraproducente quanto a contenda entre o professor de história e o ator figurante para saber quem é o autêntico e quem é o duplicado. No fim das contas, esses textos se (con)fundem e se (re)combinam através de intricadas teias intermidiais, nas quais autores e adaptadores fazem contribuições (co)autorais por intermédio da constante atualização das tramas e da sugestão de múltiplos desdobramentos desses mesmos materiais. De maneira análoga ao final do romance de Saramago - que, ao invés de encerrar a contenda entre 
sósias, sugere a abertura de novas frentes de fragmentação do herói -, as atividades adaptativas tendem a propiciar padrões de desenvolvimento e de multiplicação dos textos rumo a novas fronteiras intermidiais. Trata-se de um processo em permanente abertura e ressignificação, ao longo do qual as noções de originalidade e de fidelidade tendem a se fluidificar.

\section{Referências}

2001: a space odyssey. Direção: Stanley Kubrick. Intérpretes: Keir Dullea, Gary Lockwood, William Sylvester, Douglas Rain et al. Beverly Hills: Metro-Goldwyn-Mayer, 1968. Blu-ray.

Andersen, Hans Christian. A sombra. Tradução de Heloisa Jahn. In: Calvino, Italo (Org.). Contos fantásticos do século XIX: o fantástico visionário e o fantástico cotidiano. São Paulo: Companhia das Letras, 2004, p. 285-297.

Arrival. Direção: Denis Villeneuve. Intérpretes: Amy Adams, Jeremy Renner, Forest Whitaker et al. [S.l.]: FilmNation Entertainment; Lava Bear Films; Paramount Pictures, 2016. Blu-ray.

Ayme, Marcel. Les Sabines. In: Ayme, Marcel. Le passe-muraille. Paris: Gallimard, 2012, p. $20-58$.

BELANGER, Joseph. Embracing the enemy: an interview with Enemy director, Denis Villeneuve. Black Sheep Reviews [S.l.], 1 Jul. 2014. On-line. Disponível em: <http://www.blacksheepreviews.com/the-black-sheep-interview-denis-villeneuve-enemy>. Acesso em: 13 jun. 2017.

Borges, Jorge Luis. El otro. In: Borges, Jorge Luis. El libro de arena. Madrid: Alianza, 1986, p. $1-10$.

Calbucci, Eduardo. Saramago: um roteiro para os romances. Cotia: Ateliê, 1999.

Carroll, Noël. Visual metaphor. In: Carroll, Noël. Beyond aesthetics: philosophical essays. Cambridge: Cambridge University Press, 2001, p. 347-368.

Chevalier, Jean; Gheerbrant, Alain. Dictionnaire des symboles: mythes, rêves, coutumes, gestes, formes, figures, couleurs, nombres. Paris: Jupiter, 1982.

Cirlot, Juan Eduardo. Diccionario de símbolos. 10th ed. Madrid: Siruela, 2006.

Clüver, Claus. Inter Textus / Inter Artes / Inter Media. Aletria, Belo Horizonte, v. 14, n. 1, p. 11-41, 2006.

DeAd Ringers. Direção: David Cronenberg. Intérpretes: Jeremy Irons, Geneviève Bujold et al. [S.l.]: Morgan Creek, Téléfilm Canada, 1988. DvD.

Dostoiévski, Fiódor. O duplo. Rio de Janeiro: 34, 2011.

Ehrlich, David. Tiff review: Enemy. mTV News, [S.1.], 13 Sept. 2013. On-line. Disponível em: <http://www.mtv.com/news/2 771092/enemy-review/>. Acesso em: 13 jun. 2017.

Enemy. Direção: Denis Villeneuve. Intérpretes: Jake Gyllenhaal, Mélanie Laurent, Sarah Gadon, Isabella Rossellini et al. [S.1.]: Pathé, Televisión Española, 2013. DVD.

Eyes wide shut. Direção: Stanley Kubrick. Intérpretes: Tom Cruise, Nicole Kidman, Sydney Pollack, Rade Šerbedžija et al. [S.l.]: Pole Star, Hobby Films, Warner Bros., 1999. DvD. 
Gaudreault, André; Marion, Philippe. Transécriture and narrative mediatics: the stakes of intermidiality. In: STAM, Robert; RAEngo, Alessandra (Ed.). A companion to literature and film. Oxford: Blackwell, 2004, p. 58-70.

Genette, Gérard. Palimpsestes: la littérature au second degrée. Paris: Seuil, 1982.

Hutcheon, Linda. A theory of adaptation. New York: Routledge, 2006.

IbÁÑez, María Jesús Pérez; Jurado, Francisco García. El múltiple regreso de Saramago a Plauto: el tema del doble. Castilla, Valladolid, n. 28-29, p. 171-202, 2004.

Jakobson, Roman. Aspectos linguísticos da tradução. In: JAKobson, Roman. Linguística e comunicação. 14. ed. Tradução de Izidoro Blinkstein e José Paulo Paes. São Paulo: Cultrix, 1991, p. 63-72.

JAMESON, Fredric. The ancients and the postmoderns: on the historicity of forms. New York: Verso, 2015.

Kimmel, Michael. Masculinity as homophobia: fear, shame, and silence in the construction of gender identity. In: Murphy, Peter F. (Ed.). Feminism \& masculinities. Oxford: Oxford University Press, 2004, p. 182-199.

Koch, Ingedore Grunfeld Villaça; Bentes, Anna Christina; Cavalcante, Mônica Magalhães. Intertextualidade: diálogos possíveis. São Paulo: Cortez, 2007.

LANE, Anthony. Double trouble. The New Yorker, New York, 17 Mar. 2014, p. 78-79. Disponível em: <https://goo.gl/qmeAP2>. Acesso em: 13 jun. 2017.

Mazlström. Direção: Denis Villeneuve. Intérpretes: Marie-Josée Croze, Jean-Nicolas Verreault et al. [S.l.]: Max Films, Téléfilm Canada, 2000. DVD.

Manguel, Alberto. Twins in a spin. The Guardian, Londres, 7 Aug. 2004. On-line. Disponível em: <https://goo.gl/hGsLof>. Acesso em: 13 jun. 2017.

Melnyk, George. Film and the city: the urban imaginary in Canadian cinema. Edmonton: Athabasca University Press, 2014.

Milosevic, Irena; Mccabe, Randi E. (Ed.). Phobias: the psychology of irrational fear. Santa Barbara: ABC-Clio, 2015.

Mitterand, Henri. 100 filmes: da literatura para o cinema. Tradução de Clóvis Marques. Rio de Janeiro: BestSeller, 2014.

Moisés, Massaud. A literatura portuguesa. 37. ed. São Paulo: Cultrix, 2013.

Morice, Jacques. Denis Villeneuve: Prisoners est un film douloureusement américain, proche d'un western. Télérama, Paris, 9 oct. 2013. On-line. Disponível em: <https://goo.gl/UftvOk>. Acesso em: 13 jun. 2017.

Mouren, Yannick. Le film comme hypertexte: typologie des transpositions du livre au film. Poétique: Revue de Théorie et d'Analyse Littéraires, Paris, n. 93, p. 113-122, 1993.

Mourinha, Jorge. Os problemas de adaptar Saramago. Público, Lisboa, 19 jun. 2014. Online. Disponível em: <https://goo.gl/I4qxj3>. Acesso em: 13 jun. 2017.

Müller, Adalberto. Apresentação. In: Müller, Adalberto; Scamparini, Julia. (Ed.). Muito além da adaptação: literatura, cinema e outras artes. Rio de Janeiro: 7Letras, 2013, p. 7-11.

Ortiz, Izaskun Arrese. Woody Allen sueña a Shakespeare: derivatives y auteurism. In: Pardo, Pedro Javier; Zapatero, Javier Sánchez (Ed.). Sobre la adaptación y más allá: 
trasvases filmoliterários. Salamanca: Ediciones Universidad de Salamanca, 2014, p. 4146.

Ovide. Les métamorphoses. Traduction de Joseph Chamonard. Paris: Garnier Frères, 1953.

Plauto. Anfitrião. Tradução de C. A. L. Fonseca. Lisboa: Edições 70, 1993.

PoE, Edgar Allan. William Wilson. In: PoE, Edgar Allan. Complete Tales \& Poems. New Jersey: Castle, 2002, p. 555-568.

Prisoners. Direção de Denis Villeneuve. Intérpretes: Hugh Jackman, Jake Gyllenhaal, Viola Davis et al. [S.l.]: Alcon Entertainment, Warner Bros., 2013. DVD.

RAJEWSKY, Irina O. Intermidiality, Intertextuality and remediation: a literary perspective on intermidiality. Intermédialités: Histoire et Théorie des Arts, des Lettres et des Techniques, Montréal, n. 6, p. 43-64, 2005.

RAmond, Charles-Henri. Enemy: méandres identitaires. Séquences, Québec, n. 290, p. 53, 2014.

SARAmago, José. A caverna. Lisboa: Caminho, 2000b.

Saramago, José. As intermitências da morte. São Paulo: Companhia das Letras, 2005.

SARAmago, José. Ensaio sobre a cegueira. São Paulo: Companhia das Letras, 1995.

Saramago, José. Memorial do convento. 30. ed. Rio de Janeiro: Bertrand Brasil, 2004.

Saramago, José. O ano da morte de Ricardo Reis. 15. ed. Lisboa: Caminho, 2000a.

Saramago, José. O Evangelho segundo Jesus Cristo. Rio de Janeiro: Record, 1991.

Saramago, José. O homem duplicado. Lisboa: Caminho, 2002.

Scius, Michael. Enemy: Explication et Décryptage. Cinérama, [S.l.], 30 May 2014. Disponível em: <https://goo.gl/xGnmpJ >. Acesso em: 13 jun. 2017.

Scott A. O. When your twin is far more interesting. The New York Times, New York, Movies Sec., C4, 14 Mar. 2014.

SegarRa, Marta. Traces du désir. Paris: Campagne Première, 2008.

Shakespeare, William. The comedy of errors. In: Shakespeare, William. The complete works of William Shakespeare. London: Geddes \& Grosset, 2006, p. 90-101.

Sobreira, Ricardo. Capitu was more of a woman than i was a man: ambivalence and sexual ambiguity in a television adaptation of Dom Casmurro. Luso-Brazilian Review, Madison, v. 52, n. 2, p. 37-53, 2015.

Stam, Robert. A literatura através do cinema: realismo, magia e a arte da adaptação. Tradução de Marie-Anne Kremer e Gláucia Renate Gonçalves. Belo Horizonte: UfmG, 2008.

STAм, Robert. Film theory: an introduction. Oxford: Blackwell, 2000.

Stam, Robert. Teoria e prática da adaptação: da fidelidade à intertextualidade. Ilha do Desterro, Florianópolis, n. 51, p. 19-53, 2006.

Stevenson, Robert Louis. O médico e o monstro: dr. Fekyll e mr. Hyde. 2. ed. Tradução de Flávia Villas Boas. Rio de Janeiro: Paz e Terra, 1995.

UN 32 août sur terre. Direção: Denis Villeneuve. Intérpretes: Pascale Bussières, Alexis Martin et al. [S.l.]: Max Films, Épicentre Films, 1998. DvD.

VANoye, Francis. Récit écrit récit filmique. Paris: Nathan, 1989. 
Vieira, Jorge de Albuquerque. Liminaridade e transdisciplinaridade. In: Silva, Rafael Souza (Ed.). Discursos simbólicos da mídia. São Paulo: Loyola, 2005, p. 107-124.

Wickman, Forrest. What should we make of Enemy's shocking ending?" Slate, [S.1.], 14 Mar. 2014. On-line. Disponível em: <https://goo.gl/az0lnq>. Acesso em: 13 jun. 2017.

Wilde, Oscar. The picture of Dorian Gray. In: Wilde, Oscar. The collected works of Oscar Wilde. London: Wordsworth, 1997, p. 1-154.

Wolman, Benjamin B. Contemporary theories and systems in psychology. 2nd ed. New York: Plenum, 1981.

Recebido em 19 de fevereiro de 2017.

Aprovado em 29 de maio de 2017.

\section{Resumo/Abstract/Resumen}

Duplicação e originalidade em uma adaptação fílmica do romance $O$ homem
duplicado,de José Saramago Ricardo Sobreira

O presente estudo objetiva analisar o filme Enemy (2013), a adaptação ambígua e controversa do romance $O$ homem duplicado (2002), do escritor português José Saramago. A investigação interdisciplinar empreendida neste trabalho problematiza as noções tradicionais de fidelidade e de originalidade com o propósito de caracterizar as adaptações fílmicas como transposições intermidiais em que múltiplos códigos intersemióticos interagem entre si. Com o intuito de fundamentar tais conceitos, argumentamos que, apesar de Enemy alterar elementos do texto adaptado, o filme reacentua a crise psicológica e a fragmentação identitária vivenciada pelo(s) protagonista(s) romanesco(s) por meio de uma construção cinematográfica de símbolos complexos e de metáforas visuais.

Palavras-chave: adaptação, intermidialidade, literatura portuguesa, identidade, José Saramago, Denis Villeneuve.

\section{Duplication and originality in a film adaptation of the novel The double, by José Saramago}

\section{Ricardo Sobreira}

This study aims at analyzing the film Enemy (2013), the equivocal and disputed adaptation of The double (2002), a novel by the Portuguese author José Saramago. The interdisciplinary investigation conducted here problematizes traditional notions of fidelity and originality for the purpose of characterizing film adaptations as intermidial transpositions in which multiple intersemiotic codes interact. In order to substantiate such concepts, I argue that although Enemy changes portions of the adapted text, it re-accentuates the psychological crisis and identity fragmentation experienced by the novel protagonist(s) by means of a careful cinematic construction of complex symbols and visual metaphors. 
Keywords: adaptation, intermidiality, Portuguese literature, identity, José Saramago, Denis Villeneuve.

\section{Duplicación y originalidad en una adaptación filmoliteraria de la novela El hombre duplicado, de José Saramago}

Ricardo Sobreira

El objetivo de este análisis es reflexionar sobre la película Enemy (2013), una adaptación ambigua y controvertida de El hombre duplicado (2002), una novela del escritor portugués José Saramago. La investigación interdisciplinaria planteada en este estudio problematiza las nociones tradicionales de fidelidad y de originalidad con el objetivo de presentar las adaptaciones filmoliterarias como transposiciones intermediales en las cuales múltiples códigos intersemióticos interaccionan. Con el propósito de fundamentar estos conceptos, sostenemos que Enemy sin embargo cambia elementos del texto adaptado, pero la película enfatiza la crisis psicológica y la fragmentación de la identidad soportadas por el(los) protagonista(s) novelesco(s) por intermedio de la construcción cinematográfica de símbolos complejos y metáforas visuales.

Palabras clave: adaptación, intermedialidad, literatura portuguesa, identidad, José Saramago, Denis Villeneuve. 